\title{
TRES VERSIONES DE LA INTIMIDAD
}

\author{
Sergio Cueto
}

Universidad Nacional de Rosario

Resumen: A través de tres motivos y tres referencias diferentes, el retrato en una litografía de Paul Klee, la conversación en un haiku de Ryota y la música en un poema de T. S. Eliot, el trabajo se propone interrogar el estatuto de la intimidad como experiencia del sí mismo.

Palabras clave: Intimidad, Retrato, Conversación, Música

\begin{abstract}
Through three motifs and different references, portrait in a lithograph of Paul Klee, conversation in haiku of Ryota and music in a poem of T. S. Eliot, the work aims to interrogate the status of intimacy as experience of self.
\end{abstract}

Keywords: Intimacy, Portrait, Conversation, Music 


\section{Retrato}

La obra, una litografía pintada con acuarela de 1919, lleva por título Versunkenheit, que habitualmente se traduce por Ensimismamiento, y representa un rostro masculino en el que de inmediato sorprenden los amplios y sinuosos párpados de dos ojos apretados, los gruesos labios estriados de una boca también prieta y la ausencia de ambas orejas. El rostro se ofrece no sólo cerrado al mundo y encerrado en sí sino ante todo profundamente vuelto sobre sí mismo, hundido en lo más hondo de sí, y sin embargo sin hallar en ese fondo el reposo sino todavía el hundimiento, como si el sí mismo fuera, precisamente, el hundimiento en sí. Ese hundimiento del que puede decirse que es la experiencia de sí mismo sólo en cuanto es el sí mismo en su experiencia es lo que se llama el ensimismamiento. Lo que el ensimismamiento es lo sabemos porque nos lo enseña el rostro que vemos en el cuadro. El cuadro expone abiertamente el ensimismamiento, a tal punto que no es hablar figuradamente decir que el ensimismamiento lo vemos pintado en el rostro, que está pintado como rostro en el cuadro. De forma que el sí mismo se cierra, sin duda, en el rostro que se cierra, pero se cierra sobre el afuera. Por eso el hundimiento no es el recogimiento en el fondo de sí sino el hundimiento en el hundimiento mismo, el hundimiento del hundimiento, y por sí mismo ya la exposición del hundimiento como tal. Esa exposición es lo que pinta el cuadro. El cuadro es un retrato. Es el retrato del pintor que pintó el cuadro: Paul Klee. El cuadro es lo que se llama un autorretrato. Pero el cuadro no sólo no se titula así, como es costumbre, sino que al 
principio cuesta reconocer que lo sea. Ello obedece, seguramente, a que es un autorretrato pintado con los ojos cerrados. El pintor tuvo que cerrar los ojos para verse tal como lo vemos pintado en el cuadro. En el retrato se ve lo que el pintor no pudo haber visto jamás, aquello que vio cerrando los ojos y ahora nos mira con los ojos cerrados. La mirada del retrato no es el resultado de la percepción del yo del pintor sino la visión del sí mismo viéndose, es decir, hundiéndose en su invisibilidad. El retrato no reproduce lo visible, hace visible. El retrato hace visible la invisibilidad de la pura visibilidad de sí. En el retrato se hace visible el hundimiento de la visión en ella misma. Ese hundimiento es lo que se llama la intimidad. La intimidad es el ensimismamiento mismo, es decir la sola emoción del sí mismo. La emoción es el movimiento a sí del ensimismamiento. Por eso en el retrato el rostro no expresa ninguna emoción particular pero expone el puro ser-emoción del ensimismamiento. Es el objeto del retrato. El retrato no reproduce el semblante, no constituye la semblanza, por ejemplo, de ese Paul Klee al que también conocemos a través de fotografías. El retrato retrata el movimiento a sí, el automismo del sí mismo. Por eso es un autorretrato: no porque en él el pintor se retrate a sí mismo sino porque es el retrato del ensimismamiento; pero no porque el ensimismamiento sea su tema sino porque es su acontecimiento, el acontecimiento de ese retrato, de ese autorretrato que se titula precisamente así: Ensimismamiento, Versunkenheit. La obra se retrata a sí misma, se autorretrata, no presenta otra cosa que el ensimismamiento propio de cualquier retrato. Es lo que emociona en ella. En ella el sí mismo se hunde en la más honda de las lejanías, pero 
acercándonos, haciéndonos próxima la lejanía como tal, y en esa proximidad permaneciendo sin embargo inalcanzable. La obra mide así la distancia a través de la que conversamos con ella. Es la medida de la intimidad.

\section{Conversación}

En su versión española, el haiku de Oshima Ryota dice así:

$$
\begin{aligned}
& \text { Sin palabras } \\
& \text { el anfitrión, el buésped } \\
& \text { y el crisantemo blanco }
\end{aligned}
$$

El tema del haiku, es decir, no tanto aquello de lo que el haiku trata sino aquello de lo que se trata en él, eso que está en él como el lugar en el que él se mueve, es la conversación. Se acostumbra a llamar conversación a cualquier intercambio de palabras. Lo que importa en la conversación es la palabra, pero la palabra en cuanto sólo sirve para el intercambio. Alguien dice algo a otro de manera que éste tenga a su vez algo que decir a lo que el primero ha dicho. Si alguno permanece en silencio o deja en silencio al otro, se dice que no sirve para conversar. La conversación se sostiene en el ininterrumpido ir y venir de la palabra. Pero ese vaivén, que constituye el sentido mismo de la conversación, sólo no se interrumpe por obra de la interrupción. Es preciso que uno se calle para que el otro hable, que uno y otro permanezcan alternadamente en silencio para que la palabra sea posible. Los interlocutores se intercambian la palabra gracias al silencio, pero el silencio, que 
permite el intercambio, es lo que no se intercambia. El silencio es como la respiración sin límites de la conversación. La conversación respira con la palabra, pero su respiración es el silencio. El anfitrión y el huésped están sin palabras en el haiku de Ryota. No se intercambian nada, ninguna anécdota, ninguna confesión, ninguna demanda, pero tampoco se callan lo que podrían o querrían decir ni quieren decir algo al callar de ese modo. Su silencio no es ni reticente ni expresivo. No es intencional, no viene de ellos y finalmente no les pertenece. El silencio es el lugar en el que ambos permanecen y al que han ido con la palabra. Volverse juntas dos palabras al silencio de forma que el silencio aliente en la palabra es conversar. Conversar es compartir el silencio. Comparten el silencio aquéllos que no tienen nada y no necesitan buscar algo que comunicar. Se los llama los amigos. Los amigos no son tales porque tienen un mundo en común, porque comparten un conjunto de contenidos que les permite reconocerse sino, antes e independientemente de ello, porque comunican en el silencio que es el vacío de todos los contenidos, se exponen al silencio que es la intemperie del mundo y se reconocen en el silencio que es la nada entre ellos. Entre los amigos, en efecto, no hay nada, por eso puede decirse que no son dos; pero hay nada, por eso no puede decirse que sean uno. Los amigos son no-dos. La no-dualidad de los dos, no sólo de cada uno respecto del otro sino de cada uno respecto de sí, está señalada en el haiku por la presencia del crisantemo. El crisantemo no es para los amigos un objeto del mundo o un tema de conversación, pero tampoco es para el poema un adorno o un símbolo. El crisantemo es el crisantemo, así como el huésped 
es el huésped y el anfitrión, el anfitrión. Cada uno es lo que es, pero lo es en su diferencia con los otros. Es el silencio de la diferencia el que los reúne. El crisantemo viene a señalar precisamente la in-mediatez, es decir, la nada de mediación y por eso la distancia infinita a través de la que conversan los amigos. Los amigos conversan sin rodeos, sin el rodeo, por ejemplo, del crisantemo, pero sin rodeos no quiere decir directamente, con la recíproca y homogénea rectitud del mero intercambio de palabras. En ese intercambio se pueden decir muchas cosas, pero no es posible conversar. Conversar es compartir el silencio. El silencio es la intimidad misma de los que conversan. La intimidad, aquello que cada uno es en la soledad de sí y que es la soledad en común de todos, lo que el budismo llama la no-naturaleza de Buda de los diez mil seres, se comparte en la conversación. Compartir la intimidad es intimar. Intimar es comunicarse a la intemperie las intimidades, o mejor, hacer de la intimidad la exposición en común a la intemperie y de la intemperie el ser en común de la intimidad. Intimar es conversar, cuando conversar es hacer silencio acerca del silencio. Entonces es como si el silencio viniera a la palabra, como si hablara nada más que el silencio. Es el silencio lo que escuchamos en el haiku de Ryota, el mismo en el que también nos escuchamos, como sucede en la música, al final del poema que Alberto Girri dedicó a la memoria de Gardel, en

\section{el desapego silencioso}

Con que las voces que callan juntas

Alrededor de sillas bumeantes y amaneceres 
Acostumbran a comunicarse afectos.

\title{
Música
}

En el Quinto Movimiento de The Dry Salvages, el tercero de los Cuatro Cuartetos de T. S. Eliot, se lee:

or music heard so deeply

That it is not heard at all, but you are the music

While the music lasts.

Según la versión de Wilcock:

\author{
o una música oída tan profundamente \\ que ya no se la oye, sino que uno es la música \\ mientras dura.
}

La música cumple ahí la función de instancia, es decir de ejemplo y ocasión, de lo que poco antes se llamó the unattended moment, el momento inesperado, desatendido y solitario del tiempo. El momento, por ejemplo el momento de la música, es el tiempo de lo que en el tiempo permanece afuera del tiempo. El momento viene en el tiempo, pero no es una parte del tiempo. Él es la venida misma del tiempo. Todo lo que viene en el tiempo viene en el momento, pues el momento es el tiempo propio del movimiento. El momento es el movimiento desde la perspectiva del tiempo. Ahora bien, como todo lo que se mueve, la música se mueve en el tiempo. Moverse en el tiempo es ser finito. El movimiento es la vida de lo que se mueve, pero lo que solamente vive solamente puede morir. 
Después de moverse, en efecto, la música se detiene, entra en el silencio. El silencio es el límite exterior que señala el fin de la música, en el que la música muere con la última nota. Pero sucede que la música no es una mera sucesión de notas. La música es forma. La forma es la composición del sonido con el silencio. Cada nota está en la música a tal punto expuesta al silencio que el silencio es la intimidad misma de cada nota y de la música toda. Porque está constantemente expuesta al fin, la música no tiene su fin afuera de ella misma ni es ella misma su propio fin. Por eso, igual que un jarrón chino, dice Eliot, la música descansa en el movimiento y se mueve en la inmovilidad. Ello tiene lugar en el momento. El momento no es el hito que permite distinguir, determinar y distribuir pasado y futuro sino el intervalo en el que el futuro ya se recuerda, el pasado todavía se espera y el presente es la instancia de un puro paso que como tal no pasa. El momento es el tiempo propio del movimiento. En la música escuchamos el tiempo. Tal vez nunca escuchamos otra cosa. Al oído se lo llama, en efecto, el susurrante caracol del tiempo. Pero la música es el devenir forma del tiempo, por eso ella nos enseña mejor que nadie lo que quiere decir escuchar. Escuchar no es oír un ruido o comprender un sentido. Escuchar es exponerse a la venida de lo que está partiendo, a la partida de lo que aún no llega. Lo que se escucha no está presente ante el oyente como un objeto; está en él, en el fondo de su oído, pero de forma que tampoco él está ante lo que escucha como un sujeto recogido en sí sino de entrada expuesto en lo que escucha. En tal sentido se dice que el oyente es la música, que la música y él son lo mismo. Esa mismidad no designa la identidad de dos substancias sino 
la singularidad de una experiencia. Yo no escucho la música, pero la música se escucha en mí, de modo que en relación a ella no soy un escucha sino más bien la escucha, es decir el lugar de una pura relación a sí. Esa relación es lo que se llama la intimidad. La intimidad es el único contenido de la música. Por eso la música, que no habla de nada que me sea particularmente propio, me habla sin embargo solamente de mí, es para mí la experiencia sin atributos de mí mismo. Una experiencia sin atributos es una experiencia sin refugio. No hay refugio, ni mundo ni yo, en la intimidad de la música. La música es la forma de la intimidad.

\section{Referencias bibliográficas}

Eliot, T. S. (1977). Cuatro Cuartetos. Buenos Aires: Huascar.

Silva, A. (2005). El libro del Haiku. Buenos Aires: bajo la luna.

\section{Fuente pictórica}

Klee, P. (1919). Versunkenheit. Berna: Colección Felix Klee.

Fecha de recepción: 11/05/2015

Fecha de aprobación: 23/06/2015 